\title{
Conceitos e concepções sobre alfabetização no programa ler e escrever
}

\author{
Tânia Medeiros Aciem ${ }^{1}$ \\ Orcid: https://orcid.org/0000-0001-9564-0024 \\ Celso do Prado Ferraz de Carvalho ${ }^{2}$ \\ Orcid: https://orcid.org/0000-0001-8703-8236
}

\begin{abstract}
Resumo
O texto em tela tem como objeto de análise o Programa Ler e Escrever, implementado a partir de 2008, pela Secretaria de Estado da Educação de São Paulo - SEE/SP, para os anos iniciais do Ensino Fundamental - EFAI, nas escolas da rede estadual de ensino de São Paulo. O Programa Ler e Escrever fez parte de um amplo processo de reorganização da educação pública do Estado de São Paulo, denominada São Paulo faz Escola que, entre outras medidas, implementou uma política de reorganização do currículo das escolas da rede estadual de ensino de São Paulo. Nosso intento é analisar conceitos e concepções sobre alfabetização, mais precisamente a concepção curricular ou as concepções curriculares que nortearam as ações e as propostas para o EFAI no Programa Ler e Escrever, expressos em autores que são referências nos documentos que fundamentam o programa, especificamente Ana Teberosky e Beatriz Cardoso, Luiz Carlos Cagliari, Emília Ferreiro, Magda Soares, Jussara Hoffman, Délia Lerner e Telma Weisz.
\end{abstract}

Palavras-chave: Secretaria de Estado da Educação de São Paulo. Programa Ler e Escrever. Alfabetização.

\begin{abstract}
The text on screen has as object of analysis the Read and Write Program, implemented since 2008, by the São Paulo State Secretariat of Education - SEE / SP, for the initial years of Elementary Education - EFAI, in state schools of teaching in São Paulo. The Read and Write Program was part of a broad process of reorganizing public education in the State of São Paulo, called São Paulo do Escola, which, among other measures, implemented a policy of reorganizing the curriculum of schools in the state of São Paulo. . Our intention is to analyze concepts and conceptions about literacy, more precisely the curricular conception or the curricular conceptions that guided the actions and proposals for the EFAI in the Read and Write Program, expressed in authors who are references in the documents that support the program, specifically Ana Teberosky and Beatriz Cardoso, Luiz Carlos Cagliari, Emília Ferreiro, Magda Soares, Jussara Hoffman, Délia Lerner and Telma Weisz.
\end{abstract}

Keywords: São Paulo State Department of Education. Read and Write Program. Literacy.

\footnotetext{
${ }^{1}$ Doutoranda em Políticas Educacionais, Universidade Nove de Julho - SP, tania.aciem@gmail.com

2 Professor Titular do Programa de Pós-graduação em Educação, Universidade Nove de Julho - SP, cpfcarvalho@gmail.com
} 


\section{Introdução}

O Programa Ler e Escrever é um programa de alfabetização instituído a partir de 2008, pela Secretaria de Educação do Estado de São Paulo (SEE/SP), com o objetivo de resolver os problemas existentes na rede estadual de ensino com o processo de alfabetização. Neste artigo, nosso objetivo é problematizar os principais conceitos e concepções sobre alfabetização que nortearam o currículo no EFAI, que orientam os documentos elaborados desde a origem do programa. Faremos tal análise tendo como referência autores que são citados nos documentos quando esses apresentam os fundamentos pedagógicos do programa e a concepção curricular para os anos iniciais do processo de alfabetização, entre eles, Ana Teberosky e Beatriz Cardoso, Luiz Carlos Cagliari, Emília Ferreiro, Magda Soares, Jussara Hoffman, Délia Lerner e Telma Weisz.

De modo geral, podemos verificar em documentos do programa, como nas Guias Curriculares, o anúncio de grande preocupação com o ensino, a aprendizagem, a alfabetização e a formação de professores. Os modelos de ensino e de aprendizagem, descritos no programa, inferiram no pressuposto de que as crianças realizavam associações para a construção do conhecimento a outros já existentes, por meio de assimilação e relação direta com o objeto pela resolução de problemas. E para um ensino eficaz foram previstas adequações curriculares, nas disciplinas de Língua Portuguesa e Matemática, em um processo para a melhoria da qualidade de ensino.

$\mathrm{Na}$ alfabetização, a aprendizagem da linguagem escrita foi prevista por meio de sondagens das hipóteses alfabéticas e dos diversos usos sociais da escrita contextualizadas. Houve, também, a instituição de metas e de prazos para a alfabetização nos anos iniciais.

Com relação à aprendizagem, nos anos iniciais do Ensino Fundamental, podemos destacar a importância da recuperação para a produção de conhecimento, o desenvolvimento da competência de leitura e escrita e a adequação curricular para os alunos sem êxito na alfabetização.

A formação de professores foi destacada como essencial na implantação do Programa Ler e Escrever, bem como para o sucesso da continuidade do curso das ações didáticas, das sequências pedagógicas e da rotina diária em sala aula, ou seja, para as orientações do trabalho em sala de aula.

A influência dos pressupostos de Piaget para a abordagem construtivista e a relevância dos pressupostos de Vygotsky para o sociointeracionismo relevaram a importância da interação para o ler e o escrever, no EFAI durante a alfabetização.

Para Piaget (1964), a constituição do pensamento racional, operacional, a construção do real para a criança decorreria na sequência dos estágios de desenvolvimento, a aprendizagem subordinava-se ao desenvolvimento e passaria por exercícios de operações com reflexões do pensamento. Os conhecimentos seriam elaborados espontaneamente pela criança pelos significantes e pelos significados, ou significações. Os primeiros significantes foram marcados por situações de acomodação aos objetos exteriores com significados. Já as significações foram cedidas pela assimilação, que predominava no jogo e equilibrava-se numa representação adaptada.

Sequencialmente, Piaget (1964) descreveu a elaboração de conceitos com relações lógicas que supunha uma representação construída em decorrência da vida social como a aquisição da linguagem. Esses estudos desencadearam a abordagem construtivista, com construções pela ação do sujeito sobre o objeto, na consideração de requisitos internos de maturação biológica propiciadas por lógicas diferentes, pelo erro construtivo recorrente de equilíbrios e desequilíbrios.

Vygotsky, Luria e Leontiev (2010), nos estudos com o empírico da criança, inicialmente, contextualizaram momentos precários para realização de uma avaliação do 
desenvolvimento infantil, porém com o passar do tempo mudanças decorreram a esse respeito. Surgiram hipóteses e estudos sob os aspectos evolutivos do ser humano, e sua associação aos estímulos externos em uma totalidade complexa.

Foram descritas categorias fundamentais para as soluções propostas, com independência do processo de desenvolvimento e do processo de aprendizagem, determinando para a criança a aprendizagem como um processo exterior, que utilizava resultados do desenvolvimento paralelamente. $\mathrm{O}$ desenvolvimento e a aprendizagem decorreriam de processos que sofreriam influências mútuas.

Vygotsky, Luria e Leontiev (2010) destacaram em seus estudos a relevância da interação com o meio para os aspectos evolutivos do ser humano que envolviam situações de aprendizagem com o mundo exterior, que decorreriam paralelamente ao desenvolvimento. $\mathrm{O}$ professor, nesse processo, seria o mediador da aprendizagem com uma abordagem sociointeracionista, que nos anos iniciais da alfabetização deveria propiciar situações para o ler e escrever.

Esses estudos desencadearam pressupostos para uma abordagem sociointeracionista, numa constituição histórica e cultural. Valorizando os fatores externos com interação, como a construção do conhecimento que careceria da internalização com mediação, em dialética constante entre o pensamento e linguagem.

A concepção curricular, quando tratamos do Programa Ler e Escrever nos anos iniciais do Ensino Fundamental, não foi homogênea, e apresentou diferentes abordagens em sua constituição. Verificamos que os pressupostos de Piaget (1964) e Vygotsky, Luria e Leontiev (2010), quanto à essa questão, foram complementares, pois Piaget valorizava as construções e reconstruções possíveis nos estágios do desenvolvimento humano, Vygotsky, Luria e Leontiev (2010) destacavam a aprendizagem decorrente de situações externas que possuíam o desenvolvimento como um processo paralelo com influências múltiplas.

O currículo não sendo neutro, condicionava a ação docente para o ensino e a aprendizagem, podendo ser prescritivo ou em ação.

Para Sacristan (2000), o currículo sempre possuiu contradições, interesses, uma prática de modelagem da ação docente, uma práxis com função cultural e socializadora com diálogos em instituições de ensino. O currículo passou a ser um elemento essencial para entendermos a prática pedagógica, podendo ser prescrito ou em ação. $\mathrm{O}$ currículo prescrito condicionava a ação docente e a reproduziria, e o currículo em ação poderia ser constituído e reconstituído na prática docente. O currículo apresentar-se-ia recheado de contradições, pedagógicas, políticas, produtivas entre outras.

Lopes (2006) descreveu que os currículos prescritivos, no Brasil, foram acentuados no cenário das reformas curriculares, que tiveram nos Parâmetros Curriculares Nacionais - PCNs ações norteadoras para educação básica, que mantiveram a tradição de pluralidade cultural. Os documentos curriculares concebidos como guias da ação curricular da escola no como fazer e não no porquê fazer, centrada na regulação dos indivíduos. Esses documentos atuariam mais como teorias instrumentais de currículo, que reforçariam uma concepção de cultura voltada ao desempenho adequado de mercado de híbridos culturais.

Os currículos segundo Pacheco (2009) e Dewey (2002) eram utilizados para avaliar e conduzir as ações pedagógicas na prática educativa quanto o ensino e a aprendizagem, com adaptações, ajustamentos e regulações exercitados e concretizados.

Para Dewey (2002) o currículo subordinava a experiência da criança na escola, e era uma fonte mecânica e formal com duas doutrinas, a disciplina (estudo) e o interesse (criança), o embate da educação antiga e da nova educação circundada em um desenvolvimento formal e o desenvolvimento vazio. Currículos eram mapas de experiências que deram certo com o assunto-matéria para o interesse da criança pela lógica ou pelo psicológico, com adaptações e ajustamentos exercitados e concretizados. 
Pacheco (2009) relacionava o currículo com a conscientização de um projeto pessoal do trabalho de acordo com William Pinar para reflexão de opções educacionais e curriculares, eram projetos de questionamento, construídos na diversidade e pluralidade de marcas pessoais e sociais, englobando diferentes contextos. Currículo relacionava-se a uma didática geral com planificação, realização e avaliação do processo ensino-aprendizagem, num sistema dinâmico sem uma estrutura pré-determinada ou como uma ação pedagógica fundamentada e implementada na prática educativa.

O desafio da concepção curricular em sua pluralidade foi destacado por Goodson (1997) e Perrenoud (2000), que se constituiria sempre socialmente, com conflitos políticos e sociais, numa progressão constante em formação continuada que envolveria a necessidade de uma abordagem formativa.

Em Goodson (1997), foram apresentados os desafios para uma construção social do currículo nacional britânico nosso ler, escrever e contar como uma proposta para reabilitação, reinvenção e reconstrução no processo de alfabetização, procurando desconstruir o pensamento simplista e tornar mais complexa a abordagem de currículos e seu papel no ensino e na aprendizagem. Um currículo não era constituído com naturalidade, ele era parte do ensino num modelo escolar de possibilidades e impossibilidades, desde o início do século XX com a sociologia do conhecimento escolar, salientada pela importância de uma investigação histórica que desmitificaria a ideia de um currículo atemporal, e instituiria o caráter conflitual, político e cultural, sempre social.

Já em Perrenoud (2000), a constituição do conceito de competência como a capacidade de mobilizar os saberes, ou seja, os recursos cognitivos para realização com pertinência para uma série de situações. Competências essas direcionadas ao ensinar, organizar e dirigir situações de aprendizagem, administrando a progressão constante no envolvimento e no trabalho em equipe.

Os estudos de Perrenoud (2000) denotariam a importância da administração do docente nos conflitos interpessoais, com elaboração, negociação de situações-problema em um projeto institucional, com visão longitudinal dos objetivos do ensino com abordagem formativa. Dimensionando, dessa maneira, a heterogeneidade dos alunos num ensino mútuo da pedagogia inspirada em Lancaster, envolvendo o aluno na aprendizagem.

Na relação com o saber, o aluno deveria ser capaz da elaboração de sua autoavaliação, com negociações de regras e contratos. Ao docente careceria análises conjuntas de situações complexas que envolvessem os ciclos de aprendizagem, lutando contra preconceitos e discriminações, administrando a formação contínua.

A seguir, apresentaremos os principais autores que influenciaram a constituição dos Guias de Planejamento e Orientações Didáticas do Programa Ler e Escrever.

\section{Principais autores, conceitos e referências do Programa Ler e Escrever}

A alfabetização no EFAI era um dos grandes problemas nacionais levantados pelas políticas educacionais. A constituição dos guias de planejamentos e das orientações didáticas para o Programa Ler e Escrever, no estado de São Paulo, a partir de 2008, tiveram a influência da concepção construtivista descrita, principalmente, por Emília Ferreiro e Ana Teberosky, desde os anos oitenta.

As principais discussões que nortearam a alfabetização e influenciaram a constituição do Programa Ler e Escrever foram decorrentes do fracasso do Ensino Fundamental, principalmente, nos anos iniciais de alfabetização abordadas por autores diversos.

De maneira geral, um marco importante para a discussão sobre alfabetização foi a criação, nos anos oitenta, do livro de Ferreiro e Teberosky sobre a Psicogênese da Língua 
Escrita, que desencadeou a abordagem construtivista com as hipóteses de escrita no processo de alfabetização de maneira ativa e inteligente.

Teberosky e Cardoso (1993) destacaram que um currículo aberto era essencial para aquisição da escrita da criança durante a alfabetização, com reflexões, registros e avanços no processo de ensino, desencadeados por meio do aprendizado pela representação da linguagem do sistema alfabético, das letras e da pontuação. O estudo desenvolvido consistia em evitar instruções prescritivas nos anos iniciais, como um receituário educativo que envolvia confronto com paradigmas diferentes por meio de comparação dos resultados obtidos pelas crianças.

A singularidade da prática educativa nas séries iniciais e na aquisição da escrita de crianças sobre o processo de ensino-aprendizagem eram abordadas, pelos professores, em situações de aprendizagem no EFAI. Contextualizadas e desenvolvidas na diversidade, na complexidade e na dificuldade da reflexão sobre a ação.

Os fundamentos pedagógicos do Programa Ler e Escrever contaram com contribuições para o processo de alfabetização, que passaria a contar com a utilização de atividades de leitura e escrita numa perspectiva teórica de currículo aberto, com utilização e aplicação social, transpondo o ambiente escolar, com novos desafios às crianças com participação como um sujeito ativo no aprender por meio da reflexão, da ação e da reflexão. (TEBEROSKY; CARDOSO, 1993).

Emília Ferreiro foi orientanda por Piaget em seu doutorado, e em seus escritos identificamos grande influência dos pressupostos de Piaget na constituição da abordagem construtivista para aquisição da leitura e escrita. Piaget (1964) em seus estudos demarcou o papel do professor como um facilitador da aprendizagem, com estudos voltados a epistemologia genética, a reversibilidade lógica e a permanência do objeto. A ação do sujeito sobre o objeto implicaria diferentes lógicas, construídas pelo erro construtivo, recorrente de equilíbrios e desequilíbrios.

Weisz (2006) constatou que no processo de alfabetização, a escola não era considerada um problema nos anos iniciais do Ensino Fundamental. A autora constatou que os pressupostos de Piaget influenciaram Ferreiro quanto à abordagem de uma nova concepção para o processo de ensino e aprendizagem, em que a criança passaria a ser o centro da aprendizagem de maneira ativa e inteligente.

Os aprendizes passariam por novas possibilidades de construções e reconstruções sobre as ideias do sistema de escrita, com produções sequenciadas para identificação das emissões sonoras, sílabas, reconhecimento das letras, ortografia, correspondência entre som e letra a serem avaliados pelo processo de construção da escrita sem mecanização de pseudotextos prontos e com participação social.

Weisz (2006) salientava que o processo de alfabetização deveria ter início assim que a criança passasse a ter contato com textos na linguagem escrita e no reconhecimento de sua função social na cultura letrada, ou seja, desde a educação infantil. A autora colaborou com a elaboração das provas do Sistema de Avaliação de Rendimento Escolar do Estado de São Paulo - SARESP, para avaliação de desempenho dos alunos das primeiras e segundas séries

Salientou a possibilidade de incluir na educação infantil, práticas sociais de leitura e escrita contínuas, em sua programação educacional que favorecessem a aprendizagem e a ampliação de possibilidades de inserção na cultura letrada, antecipada pelo ingresso de um ano a mais, na escola de Ensino Fundamental de nove anos. Para a funcionalidade dessa programação foram indicados acompanhamentos e avaliações dos professores e das escolas pela Secretaria de Educação, como maneira de garantir aos alunos dos anos iniciais a transposição com suporte pedagógico de suas dificuldades e defasagens.

Historicamente, os estudos de Soares (1999) e Ferreiro (2002) preocuparam-se com a incapacidade da escola na identificação do sujeito produtor do conhecimento, que desde os anos setenta, atribuíam esse quadro a uma patologia social, marcada nas primeiras décadas do século 
$\mathrm{XX}$, por um processo de alfabetização restrito a assinatura do nome com instruções simples. $\mathrm{O}$ século XXI é marcado por uma alfabetização para seres produtores de conhecimento, que fomentaram a identificação da insuficiência do termo alfabetização, ampliado, concomitante, a terminologia de letramento, ou seja, a instituição de uma cultura letrada em situações de leitura e escrita.

A nova democracia da cultura letrada, que abrangeria a diversidade textual, simultaneamente, contou com avanços tecnológicos que contrariariam a tradição elitista, que em percentuais diminuiria o número de analfabetos no mundo na construção de uma metalinguagem.

Essa equivalência na diferença, na alfabetização, buscava a articulação da linguagem, da escola e da sociedade, que Soares (1999) nomeou de letramento de três gêneros, com os princípios da leitura discursiva de Bakhtin e o aporte teórico, nos anos cinquenta, publicado pela UNESCO. O letramento, portanto, surgiu pela emergência do entendimento da escrita no mundo social, além da capacidade de codificação do próprio nome e escrita de um bilhete, que diferenciaria a apropriação da escrita à tecnologia para ler e escrever.

Para avaliar e medir as condições de letramento Soares (1999) referenciou, no Brasil, o precário papel do Movimento Brasileiro de Alfabetização - Mobral, no final dos anos sessenta que não cumpriu seu papel na alfabetização de pessoas adultas. Muitas pessoas que participaram do Mobral, após um ano, esqueceram as práticas de leitura e escrita por não as utilizarem com letramento, em contraponto com Cuba, também nos anos sessenta, na campanha para alfabetização de jovens e adultos com produção de materiais, realmente, tornou o povo cubano alfabetizado e letrado.

Soares (1999) destacou o conceito de letramento como importante para mundo social e sua relação intrínseca com a alfabetização e os fenômenos da linguagem, na escola e na sociedade. Os conceitos de analfabeto e alfabetizado foram discutidos no Brasil e sofreram modificações a partir dos anos quarenta, agregando não somente a assinatura do nome, como a escrita de um bilhete como essenciais para uma pessoa alfabetizada.

Portanto, havia divergência entre a apropriação da escrita e a tecnologia para ler e escrever. O século XXI foi marcado por práticas de leitura e escrita com letramento, e a leitura e a escrita passariam pela identificação de um processo complementar durante a alfabetização.

Para Ferreiro (2002) a abordagem construtivista procurou romper com as desigualdades sociais impostas pelo imperialismo linguístico para as crianças no processo de alfabetização. Ferreiro (2002) historicamente como Soares (1999) discorreu sobre o fracasso do ensino nos anos iniciais da alfabetização, que nos anos setenta, foi considerada uma patologia social das pessoas que viviam numa zona de pobreza.

No século XX surgiu o termo cultura letrada associada a ideia de letramento no processo de alfabetização, e no século XXI tivemos o plurilinguismo aplicado à diversidade contextual para compreensão da escrita, as semelhanças e diferenças entre o significante e o significado para construção de uma metalinguagem para o EFAI.

Desde a primeira fase do Programa Ler e Escrever, que previa a criação do suporte inicial para a reforma curricular, o acompanhamento da pesquisadora argentina Delia Lerner esteve presente e delineou a emergência da transformação da prática docente para alfabetização na educação básica. Fruto de várias discussões, a alfabetização dos anos iniciais e os problemas apresentados, em diversos países, desencadeou um projeto curricular atrelado a uma produção pioneira da didática da matemática.

O sistema de ensino carecia de conceituações nas mudanças decorrentes do ambiente escolar quanto à língua escrita. Como a diferenciação de ensino e de aprendizagem, que nessa segunda podemos defini-la como fruto de assimilações, construções cognitivas com enorme potencial pedagógico, já o ensino possuía intrínseca relação ao didático, ajustado ao rigor do saber científico. (LERNER, 2002). 
As práticas sociais de leitura e escrita foram descritas como o foco central e não periférico do programa escolar, e o conteúdo didático numa relação contínua com as noções com reflexões gramaticais e literárias. Essas práticas contemporâneas poderiam inferir em novas preposições curriculares e mudança de foco na concepção de ensino, que deveriam dar legitimidade à ciência e oportunizar uma didática para transmissão do saber.

Para Lerner (2002) redefinir a função do ler e escrever, reconceituação do objeto de ensino por meio das práticas sociais, dentro e fora da escola, passariam a ser uma tarefa incontestável da instituição escolar. A alfabetização, portanto, transcendeu para incorporar os alunos na cultura escrita, e a escola passou a funcionar como micro comunidade para leitores e escritores. Uma escola que produziria transformações substanciais nos alunos como sujeito ativos, capazes de resolverem problemas, seres críticos que entenderiam mensagens implícitas ou explícitas em textos, e não apenas sujeitos que conseguiriam decifrar o sistema de escrita.

Essa escola não deveria esquecer ou renunciar sua função de ensinante. Alguns questionamentos e hipóteses foram propostos por Lerner (2002), como a necessidade de mudanças de concepção de ensino. Essas mudanças tornariam os alunos leitores e escritores competentes e autonomos? Segundo ela a capacitação profissional era emergente para os professores latino-americanos, mas não suficiente para uma mudança na proposta pedagógica.

Um dos grandes desafios da escola passaria ser romper com as atividades mecânicas desprovidas de sentido, como a fabricação de sujeitos ágrafos e dos copistas receptores. A escrita deveria deixar de apresentar características avaliativas e se constituiria como objeto de ensino, como instrumento de reflexão do pensamento, da organização e reorganização do próprio conhecimento. $\mathrm{O}$ tempo passaria a ter uma função inerente ao ensino, com compreensão e produção de textos breves e simples.

O projeto curricular da escola explicitaria aspectos implícitos nas práticas sociais da linguagem, como as antecipações com fluência visual, criação de estratégias para leitura, confrontações e verificações. Ler e escrever passariam pela atuação de instrumentos poderosos, que permitiriam reorganizar o mundo e os pensamentos, com responsabilidades em assumi-los, priorizando o detrimento com a linguagem, a forma e o conteúdo na busca da comunicação pela escrita.

Lerner (2002) discutiu a abordagem construtivista, nos princípios de Ferreiro e Teberosky, que após vinte anos de publicação da Psicogênese da Língua Escrita, continuava emergente de reflexões sobre a competência de leitura e escrita pela criança, o papel do professor que, em muitas situações, ficava reduzido a espectador no processo de ensino e aprendizagem.

As práticas sociais no ler e escrever redefiniram transformações na escola de alunos ativos, críticos, capazes de resolverem problemas, com um projeto curricular poderoso para reorganização do mundo.

O estudo de Hoffmann (2005) salientou a importância da avaliação mediadora para reflexão e a construção de novas práticas pedagógicas do professor no EFAI, que dialogaria com um currículo em desenvolvimento com as metodologias de ensino, os objetivos, os conteúdos desenvolvidos e procedimentos entre outros.

A aprendizagem dos alunos estaria associada a uma pedagogia com dimensão qualitativa descrita por Perrenoud (2000), que seria aperfeiçoada no processo avaliativo para uma educação com organização curricular em suas especificidades.

Em relação à leitura e a escrita, Hoffmann (2005) propôs que o aluno deveria a aprender a aprender, a ser e a conviver com leitura, e que aprender a ler é diferente de gostar de ler. Princípios esses salientados, em parte do Relatório da UNESCO, informem de Delors, publicado em 1996, que foi uma base importante para a educação do século XXI, para reorganização do ensino e novas propostas pedagógicas para a melhoria da aprendizagem. 
O princípio de provisoriedade e de complementaridade na perspectiva mediadora privilegiariam atividades dissertativas, produções textuais, estratégias de raciocínio na construção sensível da avaliação no fazer pedagógico, que valorizou as contribuições de aprendizagem de Piaget (1964) mediadora construtivista e de Vygotsky, Luria e Leontiev (2010), num processo sócio-histórico.

A concepção formativa e mediadora e os critérios de avaliação implicariam na intervenção pedagógica, com desafios cognitivos adequados que contemplariam o currículo estabelecido, nos fazeres e saberes dos alunos comparados a algum parâmetro ou expectativa de desempenho definido, ou seja, um padrão de referência definido pela escola, pelo professor ou mesmo pelo currículo.

Cagliari (1999) quanto à alfabetização, nos anos iniciais da alfabetização, discordava do método tradicional e da abordagem construtivista pela não identificação do sistema de escrita ortográfica e a subdivisão da linguagem nos níveis de hipóteses alfabéticas. Transpôs para o centro didático a aquisição da leitura, da escrita e da noção de ortografia. Os anos oitenta foram marcados pela fonética, fonologia e sistema de escrita por meio da alfabetização.

Luiz Carlos Cagliari escreveu o livro Alfabetizando sem o bá-bé-bi-bó-bu, propôs uma nova proposta de metodologia da alfabetização que desconsiderou o método silábico, com ou sem cartilhas, para a prática de ensinar a ler e escrever. O centro didático da discussão passou a ser a aquisição da leitura, da escrita e a noção de ortografia que era ausente em abordagens até então.

A estreita relação entre a fala e a escrita e o som com a escrita (codificação), apresentaram peculiaridades, de acordo com Cagliari (1999), pois na fala não nos preocupamos, como na escrita com os sons das palavras, e sim com as ideias a serem transmitidas. A decifração utilizada na leitura tornavase, apenas, uma das estratégias para decodificação que relacionava a letra com o som.

Para a prática pedagógica o autor realizou indicações na construção da escrita como: o reconhecimento dos nomes das letras, o seu valor funcional, fonético com e sem princípio acrofônico, o alfabeto, a utilização das letras, sua ordem na escrita, categorização gráfica e funcional das letras, a ortografia, o reconhecimento de uma palavra, a descoberta que nem tudo que se escreve são letras, e que nem tudo que falamos pode ser representado graficamente na escrita, como também, que o alfabeto não deveria ser utilizado para fazer transcrições fonéticas.

\section{Considerações Finais}

Na identificação da concepção curricular do Programa Ler e Escrever - SEE/SP foram emergentes políticas educacionais para alfabetização, que direcionassem o programa e seus fundamentos pedagógicos.

Dos vários autores que influenciaram a constituição do programa, encontramos abordagens diversas para os anos iniciais para o Ensino Fundamental que envolveram a leitura e a escrita, podemos destacar a presença de Ana Teberosky e Beatriz Cardoso, Luiz Carlos Cagliari, Emília Ferreiro, Magda Soares, Jussara Hoffman, Délia Lerner e Telma Weisz.

Apesar do Programa Ler e Escrever ser um programa prescritivo, notamos disputas de outras abordagens como a de Teberosky e Cardoso (1993) que sugeririam um currículo aberto que transponha os muros escolares com ação, reflexão e ação, que se aproximava do currículo em ação descrito por Sacristan (2000).

O currículo em ação subordinava a aprendizagem às interações sociais, descritas por Vygotsky, Luria e Leontiev (2010), que relegava o desenvolvimento a um processo paralelo e de mútuas representações do sujeito ativo.

Como foi destacado no processo de significação do mundo por Hoffmann (2005), dinamicamente, numa aprendizagem gradual por meio de ações pedagógicas com uma visão prospectiva e multidimensional com matizes de qualidade por meio da mediação. A complexidade no contexto sociocultural com um currículo em desenvolvimento por meio de 
metodologias de ensino, posturas pedagógicas, objetivos, conteúdos desenvolvidos, procedimentos avaliativos entre outros.

A multiplicidade nos ambientes significativos deveria considerar os tempos e as linguagens exploratórias e expressivas no processo avaliativo, com observação e reflexão na experiência educativa, ciclicamente, na diversidade. A aprendizagem dos alunos atenderia a uma pedagogia diferenciada, descrita por Perrenoud (2000) como dimensão qualitativa, apresentada por meio de uma avaliação mediadora, composta por um tempo de admiração dos alunos, de reflexão e de construção de novas práticas pedagógicas pelo professor num exercício de investigação, além da transmissão do conhecimento.

O processo de significação do mundo, dinamicamente, nessa abordagem transpunha a aprendizagem gradual por meio de ações pedagógicas com uma visão prospectiva e multidimensional com matizes de qualidade por meio da mediação. A complexidade no contexto sociocultural, com um currículo em desenvolvimento por meio de metodologias de ensino, posturas pedagógicas, objetivos, conteúdos desenvolvidos, procedimentos avaliativos entre outros, num padrão de referência instituído pela escola.

Weisz (2006) constatou que no processo de alfabetização, a escola não era considerada um problema no EFAI no século XX, e que mudanças decorrentes no século XXI passariam a considerar a criança no centro da aprendizagem. A abordagem construtivista, segundo a autora, pressupunha uma abordagem de uma nova concepção para o processo de ensino e aprendizagem, em que a criança passaria a ser o centro da aprendizagem de maneira ativa e inteligente, relevando os pressupostos de Piaget que influenciaram Ferreiro nessa constituição.

Concomitantemente, Soares (1999) e Ferreiro (2002) preocuparam-se com a incapacidade da escola na identificação do sujeito produtor do conhecimento, que desde os anos setenta, marcada nas primeiras décadas do século XX, e o século XXI é marcado por uma alfabetização para seres produtores de conhecimento com divergência entre a apropriação da escrita e a tecnologia para ler e escrever. O século XXI foi demarcado por práticas de leitura e escrita com letramento, com a identificação de um processo complementar durante a alfabetização.

Ferreiro (2002) priorizou a abordagem construtivista, procurou romper com as desigualdades sociais impostas pelo imperialismo linguístico para as crianças no processo de alfabetização e Lerner (2002) destacou a fragilidade da abordagem construtivista, emergente de reflexões sobre a competência de leitura e escrita pela criança, o papel do professor que, em muitas situações, ficava reduzido a espectador no processo de ensino e aprendizagem.

Pelas práticas sociais apresentadas pelos autores quanto ao ler e escrever, ao longo da discussão foi notório o discurso, de redefinição e transformação da escola, com o ideário de alunos ativos, críticos, capazes de resolverem problemas, com um projeto curricular poderoso para reorganização do mundo.

Cagliari (1999), em perspectiva de mudança, diferenciava na alfabetização o nosso sistema de escrita em alfabético com variações de transcrição fonético e ortográfico, desde o início do processo com condições de anular a variação linguística no nível da palavra. Ele discordava do método tradicional e da abordagem construtivista, que dividia a aquisição da linguagem nos níveis das hipóteses alfabéticas, por não existir uma correspondência exata com um sistema de escrita ortográfica.

A proposta de Cagliari (1999) voltada à aquisição da escrita aperfeiçoou o processo de alfabetização para as crianças, a partir dos cinco anos de idade, e para adultos num curto período de tempo para aquisição, geralmente, de dois a três meses. No Brasil representaria uma grande conquista de acordo com os dados alarmantes de analfabetismo do país, pois o conhecimento da aquisição da escrita como ciência independia estratégias de ensino variadas e transporia ao centro didático a aquisição da leitura, da escrita e da noção de ortografia.

O Programa Ler e Escrever foi decorrente das reformas educacionais, dos anos noventa, que impactaram os espaços educacionais num espaço de disputas heterogêneas, com avaliações 
em larga escala. O programa, no entanto, foi fruto de grupos heterogêneos que debateram, principalmente, sobre os aspectos de construção e mediação da leitura e escrita, como expostos neste artigo, nos anos iniciais sob diversos âmbitos.

$\mathrm{Na}$ atualidade, Programa Ler e Escrever apresenta um currículo prescritivo que no Currículo Paulista, com iniciativa da SEE/SP, desenvolve uma política composta por guias de planejamento e orientações didáticas, desenvolvidos para o alcance de habilidades relacionadas ao ensino e a aprendizagem com sugestões para rotina em sala de aula. Na gestão atual, no estado de São Paulo, o Secretário da Educação do Estado, Rossieli Soares da Silva, contempla um Mapa Estratégico, 2019-2022, com objetivo de garantir equidade nas etapas da Educação Básica na idade certa.

\begin{abstract}
Além disso, o plano tem como visão de futuro transformar o estado de São Paulo, na principal referência de educação pública do Brasil até 2022. Para 2030, a visão de futuro é que o Estado esteja entre os sistemas educacionais do mundo que mais avançam na aprendizagem. O presente ano trará uma gama de instrumentos educativos a serem implementados pelas Diretorias de Ensino e Unidades Escolares [...] O grande desafio a ser alcançado em 2020 pela comunidade escolar, é buscar ações autônomas que, vinculadas ao Mapa Estratégico 2019-2022, garantam a aprendizagem de todos os alunos. (SÃO PAULO (Estado), 2020 a, p.3)
\end{abstract}

A SEE/SP, devido às demandas da rede quanto ao ensino e a aprendizagem, ampliou as ações do Programa Ler e Escrever como foco na leitura e escrita inicialmente, e, desde 2012, passou a contar com projetos na área de matemática com Projeto Educação Matemática nos Anos Iniciais - EMAI, para ampliação no processo de formação de professores, avaliação, desenvolvimento curricular, e possibilidade de um trabalho sistemático.

O EMAI é voltado ao $1^{\circ}$ ao $5^{\circ}$ ano do Ensino Fundamental com trajetórias para o desenvolvimento curricular constituídas pelos professores, professores coordenadores e professores coordenadores dos núcleos pedagógicos. Esses materiais foram revistos e compuseram o material para o ensino da matemática, apresentado aos professores em 2013. Com a Base Nacional Comum Curricular - BNCC, em 2017 e o Currículo Paulista, em 2019, o material do projeto EMAI passou por nova revisão para continuidade a partir de 2020. (SÃO PAULO (Estado), 2020 b)

Atualmente, o material foi reorganizado por Trajetórias Hipotéticas de Aprendizagem THA, com diferentes propostas de atividades, com plano de ensino a partir dos objetivos para aprendizagem, ou seja, considerando as habilidades e as hipóteses traçadas pelos alunos dos anos iniciais do Ensino Fundamental.

\title{
Referências
}

CAGLIARI, Luiz Carlos. Alfabetizando sem do bá, bé, bi, bó, bu. São Paulo: Scipione, 1999.

DEWEY, John. A criança e o currículo. In: DEWEY, John (Org.). A escola e a sociedade e A criança e o currículo. Lisboa-Portugal: Relógio d'àgua Editores, 2002.

FERREIRO, Emília. Passado e presente dos verbos ler e escrever. São Paulo: Cortez, 2002.

GOODSON, Ivor F. A construção social do currículo. Lisboa: Educa e autor, 1997.

HOFFMANN, Jussara. O jogo do contrário em avaliação. Porto Alegre: Mediação, 2005.

LERNER, Delia. É possível ler na escola? In: LERNER, Delia (org.). Ler e escrever na escola: o real, o possível e o necessário. Trad. Ernani Rosa. Porto Alegre: Artmed, 2002. p. 74-102. 
LOPES, Alice Casimiro. Discurso nas Políticas de Discursos. Currículo sem Fronteiras, v.6, n.2, pp.33-52, Jul/Dez 2006.

PACHECO, José Augusto. Currículo: entre teorias e métodos. Conferência $4^{\circ}$ Colóquio LusoBrasileiro sobre Questões Curriculares, Universidade Federal de Santa Catarina, 2 a 4 de set 2008. Cadernos de Pesquisa, v.39, n.137, p.383-400, maio/ago. 2009.

PERRENOUD, Philippe. 10 Dez Novas Competências para Ensinar. Porto Alegre: Artmed. 2000.

PIAGET, Jean. A Formação do Símbolo na Criança: Imitação, jogo e Sonho Imagem. Tradução de Álvaro Cabral e Christiano Monteiro. Terceira Edição, 1964. Disponível em: http://dinterrondonia2010.pbworks.com/f/A+forma $\% \mathrm{C} 3 \% \mathrm{~A} 7 \% \mathrm{C} 3 \% \mathrm{~A} 3 \mathrm{o}+\mathrm{do}+\mathrm{s} \% \mathrm{C} 3 \% \mathrm{ADmbo}$

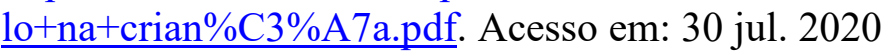

SACRISTAN, G. J. O currículo: Uma reflexão sobre a prática. Porto Alegre: Artmed, 2000.

SÃO PAULO (Estado). Ler e Escrever - Ensino Fundamental. Volume , $1^{\circ}$ ano. Guia de Orientações Didáticas. versão atualizada de acordo com currículo paulista. Governo do Estado de São Paulo. São Paulo: 2020a.

SÃO PAULO (Estado)._EMAI - Educação Matemática nos anos iniciais do Ensino Fundamental, volume $1,1^{\circ}$ ano. Organização dos trabalhos em sala de aula. material do professor. Governo do Estado de São Paulo. São Paulo: 2020 b.

SOARES, Magda. Letramento: um tema em três gêneros. Belo Horizonte: Autêntica, 1999.

TEBEROSKY, Ana; CARDOSO, Beatriz. Reflexões sobre o ensino da leitura e da escrita. Campinas, Petrópolis: Edunicamp, Vozes, 1993.

VIGOTSKY, L. S; LURIA, A. R; LEONTIEV, A. N. Linguagem desenvolvimento e Aprendizagem. 11. ed. São Paulo: Scipione. 2010.

WEISZ, Telma. Reescrevendo a Educação: proposta para um Brasil melhor. São Paulo: Ática. 2006. 